\title{
Spacing experiments with Brussels sprouts grown for single-pick harvests
}

\author{
E. W. M. Verheij
}

Institute of Horticultural Engineering (ITT), Wageningen, the Netherlands

Received 27 October 1969

\section{Summary}

In 1966 and 1967 spacing trials, comprising density, planting pattern, row orientation, crop duration and stopping of the plants as variable factors, were carried out with the hybrid variety 'Thor'.

Density effects were spectacular; planting pattern slightly influenced plant habit; no effects of row orientation could be traced.

With increasing density the estimated biological yield approached a ceiling value and remained virtually constant at still higher density. For the heavy 1967 crop ceiling yield was about twice as high as for the light 1966 crop, which is attributed to better soil conditions.

Density strongly influences plant habit. At high density plants grow taller and are more slender, which is associated with a retarded and more uniform sprout growth. Low density is best for early harvests, but sprout yields per $\mathrm{m}^{2}$ are low and do not improve with time; sprouts come in all size grades and mean weight per sprout is high. At higher density yields start later and increase rapidly with time; moreover, with increasing density sprouts become more uniform and smaller.

Good yields of sprouts of a specified grade can be obtained with a single-pick harvest, provided that the combination of density and crop duration is right. Harvesting late October instead of late September resulted in far higher sprout yields at all but the lowest density, in spite of a substantial drop in fresh plant weight. Hence the optimum spacing for sprout yield shifted to higher density with this increase in crop duration. Yields are improved by stopping, especially at higher density and for early harvests.

The tall, slender plants at higher density are well suited to mechanical stripping; the uniformity of the sprouts at these densities facilitates grading. To further reduce labour requirements more efficient methods are desirable for stopping and for defoliation at harvest.

\section{Introduction}

Stooping in a wet Brussels sprouts crop on cold winter days to strip the mature sprouts off each plant is a far from pleasant job. There has never been any hope that this task could be performed properly by a machine. However, drastic changes in cropping techniques have made a single destructive harvest feasible and this has reduced the engineering problems to such an extent that today sprouts are indeed harvested mechanically, with remarkably simple strippers.

The single harvest presupposes an even stand of crop plants and simultaneous devel- 
opment of all sprouts along the stem. The uniformity of the crop has been greatly improved by the introduction of hybrid varieties. According to Nieuwhof (1962), Haigh (1964) and Garthwaite (1968) close spacing and removal of the shoot tip - so-called stopping of the plants - promote a more even growth of the sprouts along the stem. This facilitates the stripping operation; the yields so obtained depend strongly on crop duration (Nieuwhof, 1962; Sandwell, 1969).

Experiments regarding these cropping techniques were conducted at the Institute of Horticultural Engineering, Wageningen, to support a project aimed at developing a mechanical stripper (Moltzer, 1968). After preliminary trials in 1965, a series of trials was carried out in 1966 and 1967, including plant density, planting pattern, row orientation, stopping and crop duration as variable factors.

A wide range of spacings could be accommodated in a systematic design, a modification of one of the designs proposed by Nelder (1962). The hybrid variety 'Thor' was used in all trials.

It is the object of this paper to further clarify yield-density relationships for Brussels sprouts and more in particular those effects of spacing on plant performance which have a bearing on mechanical harvest.

\section{Experimental methods}

\section{Programme of experiments}

The systematic design used for the experiments is shown in Fig. 1; it is based on a $\log -\log$ grid of plant positions and comprises variation in planting pattern and two row orientations in addition to a wide range of densities. In 1966 and again in 1967 three fields were laid out according to this design.

Table 1 Range of spacings in the systematic design and in the randomized block design

\begin{tabular}{lccc}
\hline & $\begin{array}{c}\text { Systematic } \\
\text { design }\end{array}$ & \multicolumn{2}{c}{ Randomized block design } \\
\cline { 3 - 4 } & & $\begin{array}{c}\text { density } \\
\text { trial }\end{array}$ & $\begin{array}{c}\text { planting } \\
\text { pattern trial }\end{array}$ \\
Densities, plants $/ \mathrm{m}^{2}$ & $0.65-10.4$ & $1,2,4,8$ & 2,4 \\
Ratio inter : intrarow spacing & $1: 1-4 \sqrt{2}: 1$ & $2: 1$ & $1: 1,2: 1,4: 1$ \\
Row orientations & $\mathrm{N}-\mathrm{S}, \mathrm{E}-\mathrm{W}$ & $\mathrm{N}-\mathrm{S}$ & $\mathrm{N}-\mathrm{S}$ \\
\hline
\end{tabular}

Table 2 Timing of the operations in the systematic fields in 1966 and 1967

\begin{tabular}{lccccc}
\hline Year & $\begin{array}{c}\text { Number of } \\
\text { fields }\end{array}$ & Sowing & Planting & Stopping & Harvest \\
& 2 & $18 / 3$ & $6 / 5$ & $19 / 8 *$ & $13-14 / 9$ \\
1966 & 1 & $7 / 4$ & $13 / 5$ & - & $20 / 9$ \\
1966 & 2 & $10 / 4$ & $23 / 5$ & $10 / 8-10 / 9 *$ & $25-27 / 9$ \\
& 1 & $10 / 4$ & $23 / 5$ & $10 / 8-10 / 9$ & $23-25 / 10$ \\
1967 & 1 & &
\end{tabular}

* 2 quarters per field; plants in the remaining 2 quarters were not stopped. 


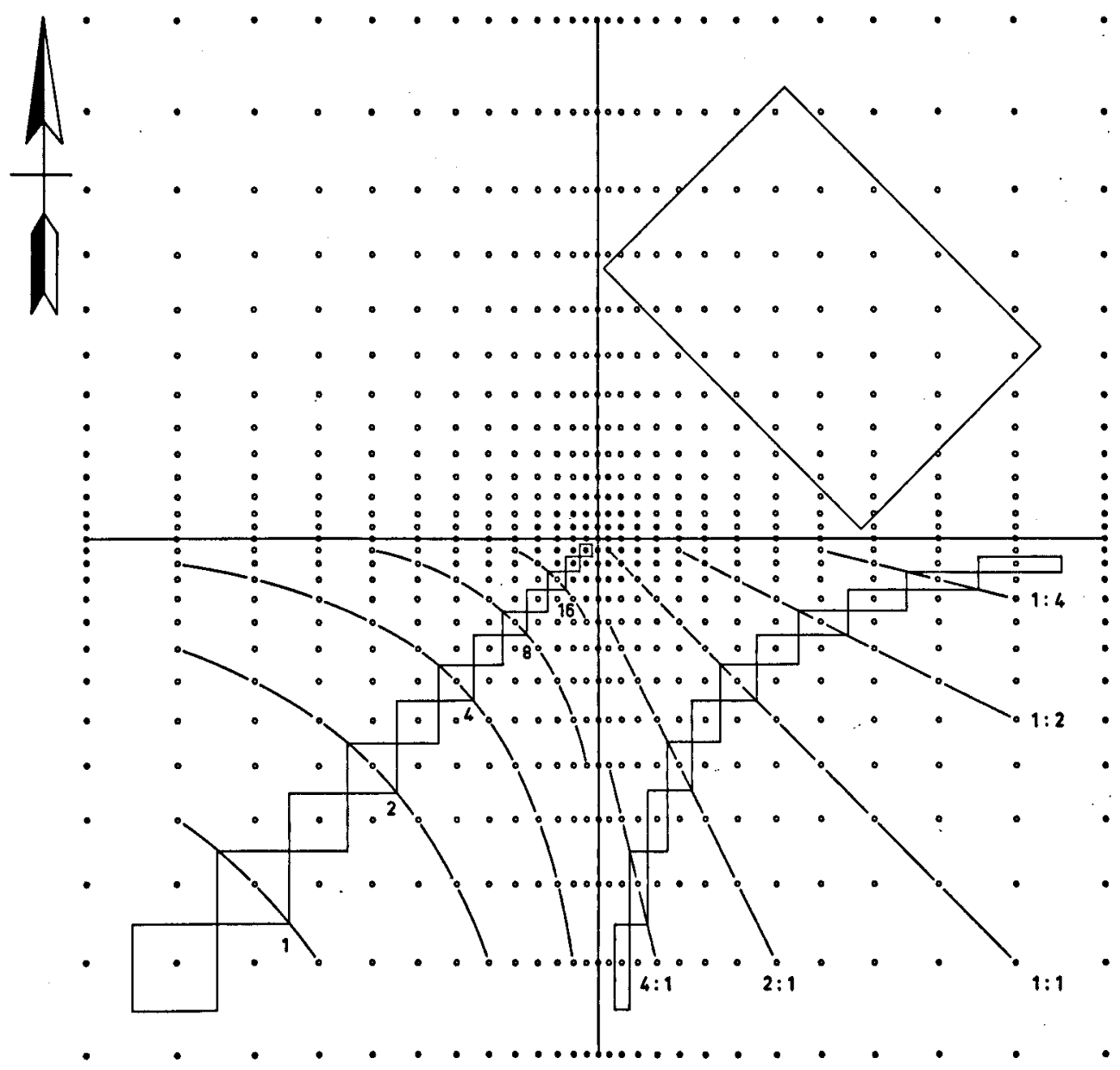

Fig. 1 The systematic design for spacing experiments, based on a log-log grid. Plant positions in oblique rectangle represent the principle of the design proposed by Nelder (1962). Black dots denote guard and filler plants.

Bottom left: curves of equal density; numbers indicate relative densities. Bottom right: lines of equal planting pattern; figures indicate the rectangularity of the area per plant.

Treatments included stopping in 1966 and stopping and crop duration (harvest date) in 1967: In 1967 the systematic design was compared with a randomized block design comprising a density trial and a planting pattern trial. Table 1 shows the range of spacings in both types of experimental design.

The timing of the operations is indicated in Table 2 for the systematic fields. The time schedule was exactly the same in the randomized block trial. All plants in the density trial were stopped and harvested on the first occasion. The plots in the rectangularity trial were split up into stopped and unstopped plants; the trial was harvested along with the last systematic field. 


\section{Cropping techniques}

'Thor' seedlings were raised in soilblocks under glass. About half the plants were discarded in the nursery and at the time of planting out; sibs could be completely eliminated in this way. The experiments were laid out on a fluvial clay soil, in 1966 on land with a poor soil structure, in 1967 on an adjacent plot with an excellent soil structure. Plant positions were marked with split bamboo sticks. The experiments were sprinkler-irrigated to ensure an even start to the plants. In 1967 plants were staked to prevent them bending away from the high density area.

The fertility status of the soil was good, but in 1966 nitrogen deficiency became manifest at high density. Therefore all experiments in 1967 were given a topdressing of nitrogen at densities over 3 plants per $\mathrm{m}^{2}$. This did improve the nitrogen status of plants at high density, but it also led to an awkward fluctuation of nitrogen content in the soil and in the crop.

In 1966 stopping was carried out on August 19 when sprouts at commercial spacings measured 1.5-2 cm in diameter. In 1967 stopping proceeded gradually, starting on August 10 with plants at low density having sprouts of $3-4 \mathrm{~cm}$ diameter. At the end of the month plants at moderate densities were stopped with largest sprouts $1-2 \mathrm{~cm}$. Stopping was completed on 10 September before sprouts in high density treatments reached a diameter of $1 \mathrm{~cm}$.

Records, measurements

The systematic design is based on single plant plots. Consequently data had to be recorded for individual plants. Records include:

plant spread, recorded periodically in relation to measurements of light interception 1 by the crop at various spacings and stages of growth;

plant height and basal stem girth at harvest, used to calculate the slenderness of the plants;

fresh weight of plants - without the roots - and dry matter content of sample plants; total sprout weight comprising all growth springing from lateral buds, down to sprouts with a diameter of $1 \mathrm{~cm}$; sprouts ranging from $1-5 \mathrm{~cm}$ in diameter were counted and weighed to obtain number and weight of marketable sprouts per plant. The unmarketable portion of total sprout weight is in fact waste material.

\section{Results}

Yield-density relationships in 1966 and 1967

Dry matter yield

In Fig. 2 the dry weight per plant and per $\mathrm{m}^{2}$ in 1966 and 1967 is presented in relation to density. For each year the curves are based on the data from the two systematic fields which were harvested early (Table 2). Weight per plant declined asymptotically with increasing density; weight per $\mathrm{m}^{2}$ rose to a maximum level, remaining virtually constant at higher density. This is in agreement with the concept of competition between crop plants, put forward by Donald (1963), Bleasdale (1966), de Wit (1960) and others. Maximum dry matter yield in both years was attained at 4 to 5 plants per $\mathrm{m}^{2}$. The 1966 crop was rather light, the 1967 crop extremely heavy; Fig. 2 shows that at

1 The results of the light studies will be reported separately. 


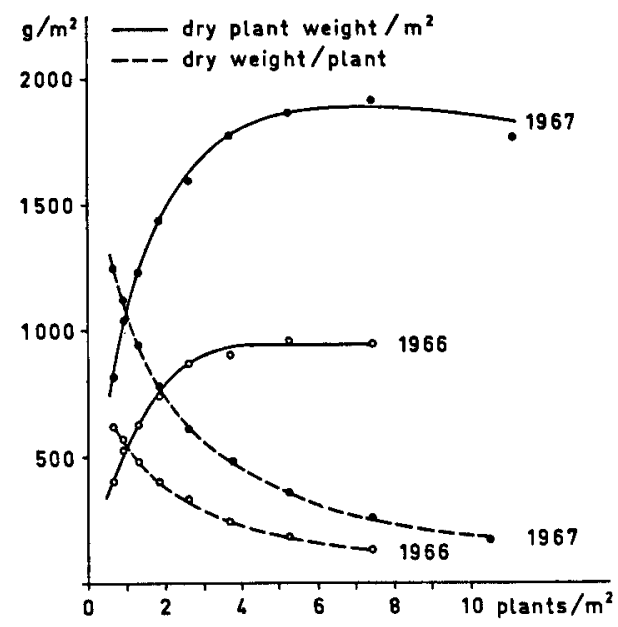

Fig. 2 Dry weight per plant and per $m^{2}$ in relation to density, in 1966 and 1967.

all densities dry matter yield per $\mathrm{m}^{2}$ in 1967 was almost twice as high as in 1966. In view of the similarity of crop duration and light conditions in 1966 and 1967, the superiority of crop production in the latter year must be largely attributed to soil factors. The type of soil was the same in both years - the experiments were laid out on adjacent fields - so the explanation must be sought in different soil conditions. Both soil structure and nitrogen status were better in 1967, and as the watertable was low, the roots could explore the soil intensively up to a depth of $1.50 \mathrm{~m}$.

Immediately after the 1967 harvest a root study was carried out by Mr J. Loeters, soil scientist of the National Horticultural Advisory Service. The results are presented in Fig. 3 (p. 96/97); data on the above-ground parts have been included in the diagram. The study was made on a diagonal of a systematic field, that is on a series of plants in a square arrangement (Fig. 1).

It appears from Fig. 3 that root number and root distribution, including depth of rooting, are very similar over a wide range of densities. Thick roots are scarce at high density, associated with small plant size. Only at the widest spacings does total root number per $\mathrm{m}^{2}$ drop noticeably. At the highest density even the presence of two neighbours of very weak stature (plants $A$ and B) does not affect root density. The small size of plant $D$ at a density of 5.2 plants per $\mathrm{m}^{2}$, however, is reflected in lower root counts.

Light measurements in late August indicated that at densities over 2.5 plants per $\mathrm{m}^{2}$ in 1967 and over 4.5 plants per $\mathrm{m}^{2}$ in 1966 the crop intercepted virtually all available light. Obviously both foliage and roots of the 1967 crop explored the environment very intensively. No root studies were made in 1966; the only apparent shortcoming of the soil was the nitrogen deficiency at very high density. Nevertheless the inferiority of dry matter production, even at densities ensuring total light interception by the crop, suggests that soil factors severely limited the efficiency of energy fixation by the leaves.

\section{Plant habit}

The reduction in plant weight with increasing density concurred with drastic changes in plant habit. Plants grew taller and stem girth was greatly reduced at close spacing; basal stem girth and plant weight were in fact closely correlated. By the end of June 1967 plant height already varied from $45 \mathrm{~cm}$ at low density to $75 \mathrm{~cm}$ at high density. 


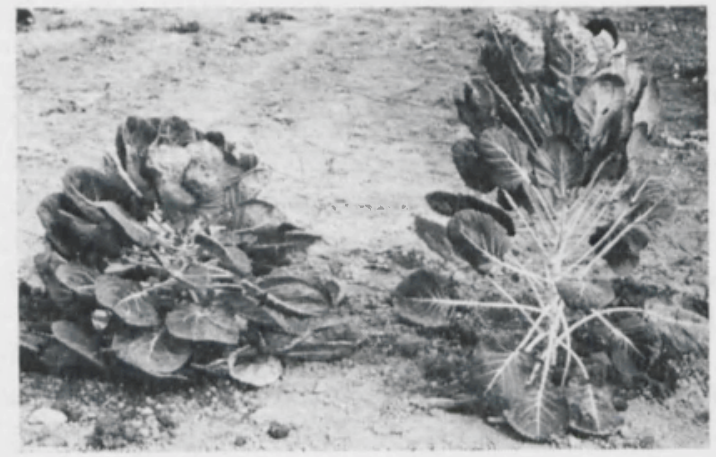

Fig. 4 Plants grown at low density (left) and fairly high density (right) shown side by side to bring out differences in plant habit.

At the end of August when plants had attained their maximum height, they measured from $75-90$ to $115-130 \mathrm{~cm}$. In 1966 maximum height increased with density from $65-70$ to $85-90 \mathrm{~cm}$. Apical dominance is very prominent in Brussels sprouts and changes in the pattern of correlative inhibition with mounting competition for light at high density probably govern the increased height growth; such changes must of course also be reflected in sprout development.

Fig. 4 shows that the superior height of the closely spaced plants stems from longer internodes and is accentuated by the upright disposition of the leaves. Crowded together the tops of these plants form a dense canopy, heavily shading the basal leaves. In widely spaced plants on the other hand, all leaves receive enough light to contribute substantially to plant growth over a long period. Thus these plants grow heavy and require a prominently tapered stem to stand firm and to cope with the accumulating transport near the stem basis. Notice in contrast the even thickness of the stem of the closely spaced plant in Fig. 4 and also the retarded sprout development.

Lodging posed some problems at the extreme densities. At low density some plants sagged under their own weight, the slender plants at very high density were easily blown over and therefore had to be staked in 1967.

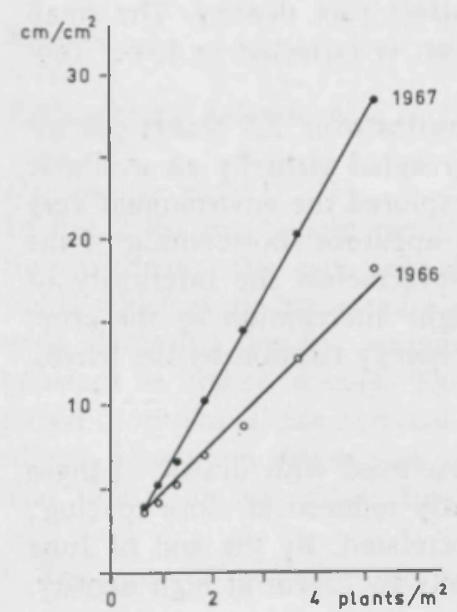

Fig. 5 Slenderness of plants, in $\mathrm{cm}$ plant height per $\mathrm{cm}^{2}$ crosssectional area at ground level, in 1966 and 1967, in relation 10 density. 


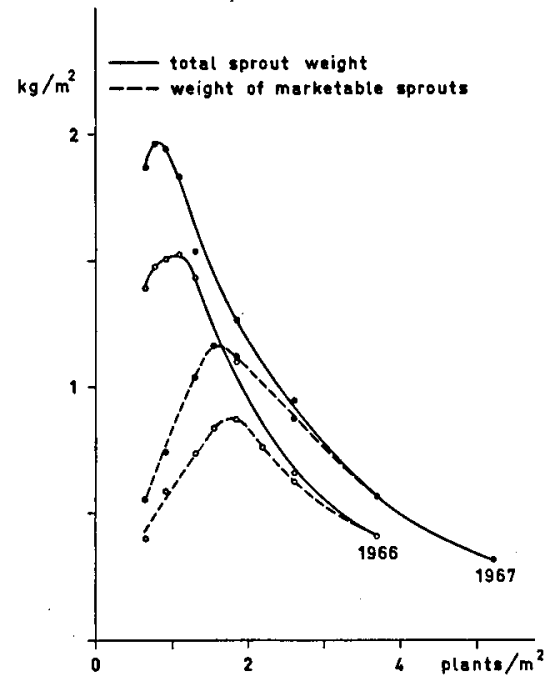

Fig. 6 Sprout weight per $m^{2}$ in relation to density, in 1966 and 1967.

The changes in plant habit with increasing density could best be characterized by the slenderness of the plants, defined as plant height in $\mathrm{cm}$ per $\mathrm{cm}^{2}$ stem cross-sectional area at ground level. As will be explained below, slender plants bear uniform sprouts, suited to single-pick harvest; also such plants can be easily stripped. Thus slenderness is a very important plant characteristic. It appears from Fig. 5 that over a fairly wide range of plant spacings slenderness was proportional to density, in both 1966 and 1967.

\section{Sprout yield}

Fig. 6 shows the relation between sprout weight per $\mathrm{m}^{2}$ and density for unstopped plants harvested early, in 1966 and 1967. Sprout yields in 1967 were higher than in 1966 at all densities, but the differences are rather small in comparison to the differences in dry plant weight (see Fig. 2). This indicates that the light 1966 crop pro-

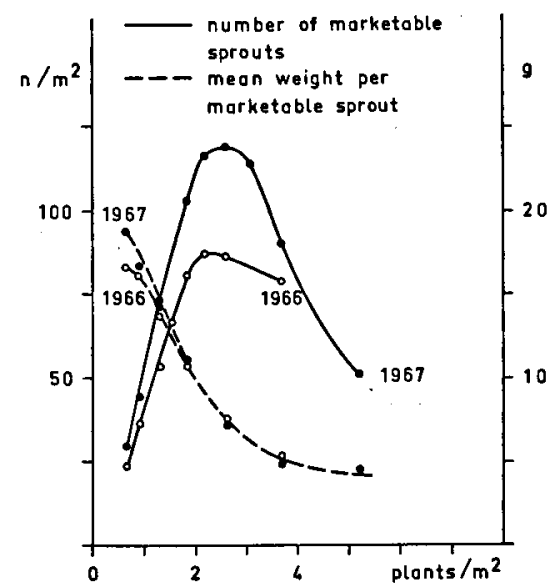

Fig. 7 Number and mean weight of marketable sprouts in relation to density, in 1966 and 1967. 


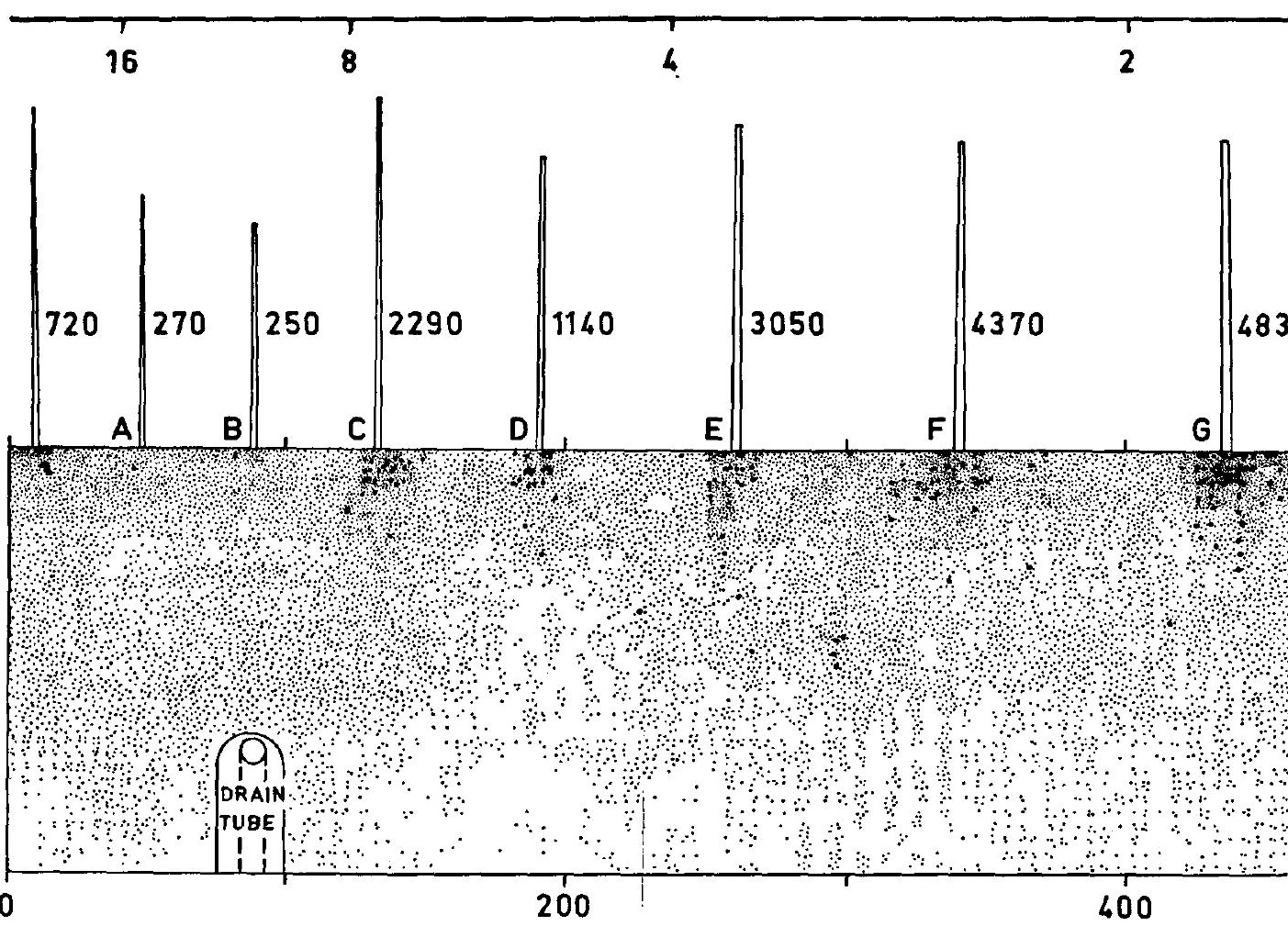

Fig. 3 Results of root counts in 5-cm squares on a soil profile along a series of Brussels sprouts plants at widening spacings, September 1967.

Root diameters: small dots $<1 / 2 \mathrm{~mm}$; heavy dots $>1 / 2 \mathrm{~mm}$.

Columns at plant positions represent plant height and stem girth at ground level; figures indicate fresh plant weight in grammes.

(By courtesy of Rijkstuinbouwconsulentschap voor Bodemaangelegenheden, Wageningen.)

duced more efficiently, that is produced more sprouts per $\mathrm{kg}$ plant weight, than the heavy crop in 1967.

It appears from Fig. 6 that the optimum densities for sprout weight per $\mathrm{m}^{2}$ coincide in both years. The curves for total sprout yield have a sharp peak at a density of about 1 plant per $\mathrm{m}^{2}$. However at low density sprouts grew so vigorously that they became too big and too loose to be marketable. Hence the yield of marketable sprouts at low density is disappointingly low; the weight per $\mathrm{m}^{2}$ reaches an optimum at nearly 2 plants per $\mathrm{m}^{2}$. At higher density the curves for marketable and for total sprout weight merge, which means that virtually all harvested sprouts were of marketable size. The market yields at the optimum of somewhat less than $1 \mathrm{~kg}$ per m 1966 and of more than $1 \mathrm{~kg}$ per $\mathrm{m}^{2}$ in 1967 are quite satisfactory for a single-pick harvest so early in the season.

The number of marketable sprouts per $\mathrm{m}^{2}$ was highest at about $2 \frac{1 / 2}{2}$ plants per $\mathrm{m}^{2}$, as shown in Fig. 7. Fig. 7 also shows that the mean weight per marketable sprout for these early harvests was vely nuch the same in both years. It drops sharply as density goes up and levels off $3 \mathrm{t} \mathrm{h}$, is than $5 \mathrm{~g}$, that is the weight of the smallest sprouts that were harvested. 


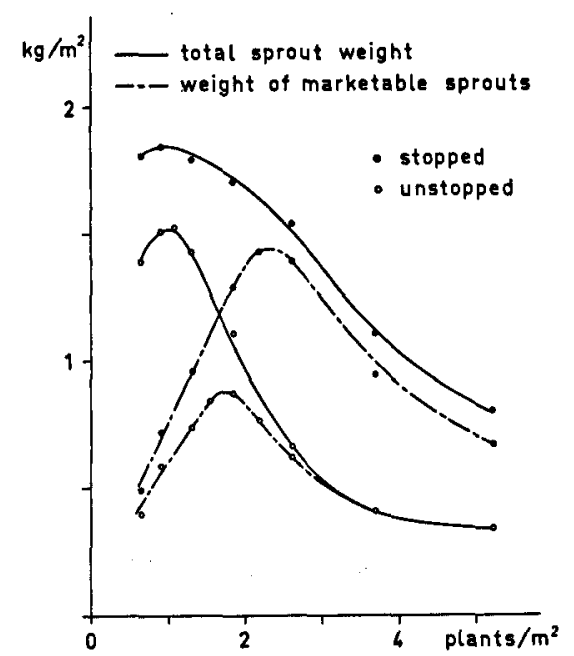

Fig. 8 Sprout weight per $m^{2}$ of stopped and unstopped plants in 1966, in relation to density.

\section{The effects of stopping}

Neither in 1966 nor in 1967 was plant weight affected by stopping. Nevertheless sprout weight per $\mathrm{m}^{2}$ at all densities was much higher for the stopped plants (Fig. 8). The curves for weight of marketable sprouts show that stopping was most effective at higher density; as a result the optimum density was higher for the stopped than for the unstopped plants. At low density the gain in weight of marketable sprouts was very small. In these widely spaced plants stopping merely shifted the zone with sprouts of marketable size to a higher region of the stem. This suggests that the response to stopping might have been better if plants at this low density had been stopped and harvested earlier.

Plants at high density responded far better because - as shown in Fig. 8 - at these densities the enhanced sprout growth brought about by stopping consisted almost entirely of marketable sprouts. The small discrepancy between total and marketable

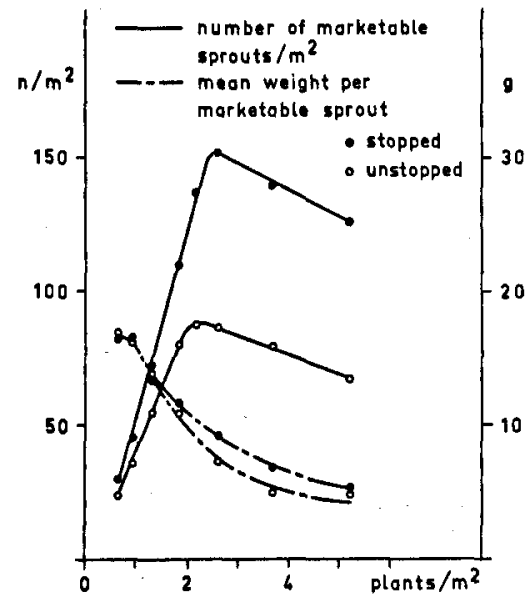

Fig. 9 The effect of stopping on number and mean weight of marketable sprouts at varying density, in 1966. 
sprout weight of stopped plants at high density is due to some quick-growing sprouts near the tops of the plants, which were too loose to be marketable. This suggests that these closely spaced plants were stopped rather early in relation to the retreat of correlative inhibition.

Fig. 9 shows that the beneficial effect of stopping largely stems from an increase in sprout numbers; mean weight per marketable sprout increases comparatively little.

Stopping can be seen as a practical means of breaking apical dominance in order to accelerate sprout growth. This results in an increase in yield (Carter, 1962; Garthwaite, 1968; Sandwell, 1969), the extent of which depends on the timing of stopping and harvesting and on density. For late harvests stopping does not increase yields at all (Sandwell, 1969), presumably because ultimately the natural disappearance of inhibition is more effective.

The greatest stimulus to sprout growth along the entire stem is probably obtained if plants are stopped when correlative inhibition is already waning, that is when little further extension growth is to be expected. It has been argued that with increasing density the inhibition persists longer; this would imply that high density crops have to be stopped later than low density crops. Indeed, as explained above, the single stopping date for all plants in the 1966 trials appeared to be late for the widely spaced plants and rather early for the closely spaced plants.

In 1967 the effects of stopping were far less prominent than in 1966. Plants at higher density were stopped only $2-4$ weeks before the September harvest, whereas it seems likely that the heavy 1967 crop in fact required a longer time to respond to stopping than the light 1966 crop. By late October 1967 the effects of stopping were clearly visible. This is borne out by Fig. 12, which also shows that stopping promotes the growth of all sprouts along the stem, not only that of the sprouts near the apex.

\section{The influence of crop duration}

Brussels sprouts are a winter crop. As growing conditions get worse with the advancing season, plant weight is bound to decline, because the activity of an increasing proportion of the foliage falls below the compensation point.

In Fig. 10 the production of the stopped plants at the two harvest dates in 1967 is presented in relation to density. In late October the ceiling level for fresh plant weight per $\mathrm{m}^{2}$ was already lower than in late September. Loss of leaves, already considerable at the first harvest, had increased considerably by late October; leaf losses increased with density. It also appears from Fig. 10 that ceiling yield for the October harvest was attained at a lower density than in September.

While the crop was on its way down, sprout production in October was still going up. This points to a considerable migration of dry matter from the dying leaves to the sprouts. Fig. 10 shows that for all densities above 1 plant per $\mathrm{m}^{2}$ sprout weight increased tremendously from September to October. The optimum density for weight of marketable sprouts per $\mathrm{m}^{2}$ shifts from about $1 \frac{1 / 2}{2}$ plant per $\mathrm{m}^{2}$ in September to 2-4 plants per $\mathrm{m}^{2}$ at the end of October, the exact optimum being obscured by the topdressing with nitrogen at higher density.

It appears from Fig. 11 that the high marketable yield in October results mainly from an increase in sprout number per $\mathrm{m}^{2}$, but the gain in mean weight per marketable sprout is also considerable.

The differential effect of crop duration on yield at varying density is a result of the 


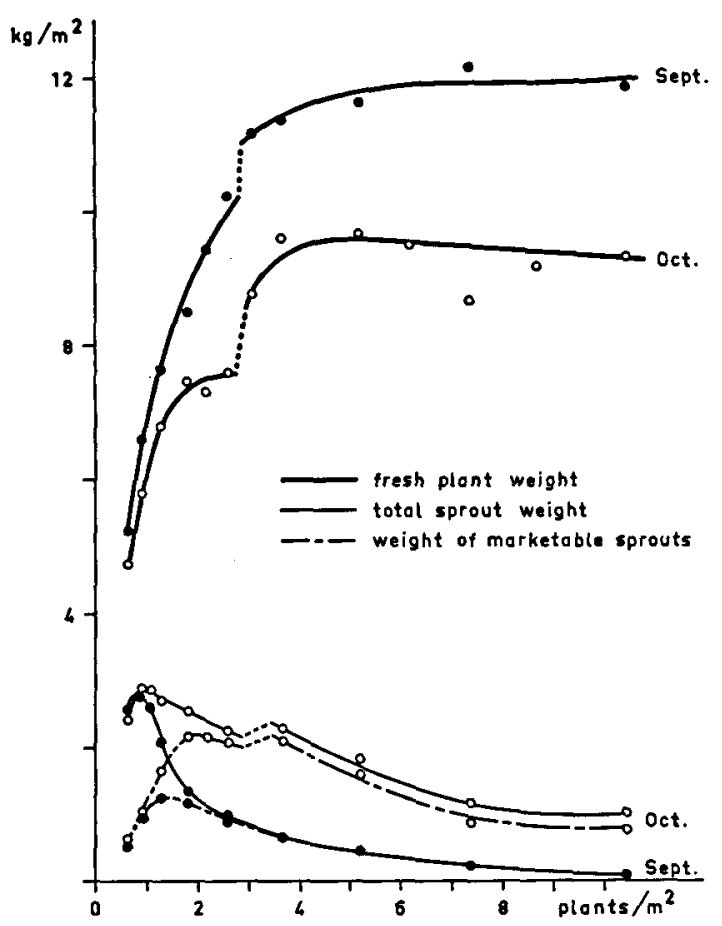

Fig. 10 Yield-density relationships for stopped plants harvested 25 September and 25 October 1967. The break in the curves for plant weight and total sprout weight is caused by the topdressing with nitrogen at higher density.

different sequence of sprout development in low and high density crops. Low densities are best for early harvest (Fig. 10, September harvest), since sprout development in plants spaced wide apart starts early. The yield is low, however, due to the small numbers of plants per ha. Also, yields at these densities do not improve much if the harvest is postponed (Fig. 10, October harvest), because what is gained by sprouts higher up the stem reaching marketable size, is lost by basal sprouts growing too big to be marketable. This implies that sprouts from these plants cannot be uniform; moreover the mean weight per sprout is rather high (Fig. 11). This all goes to say that low density crops are not suited to single-pick harvesting.

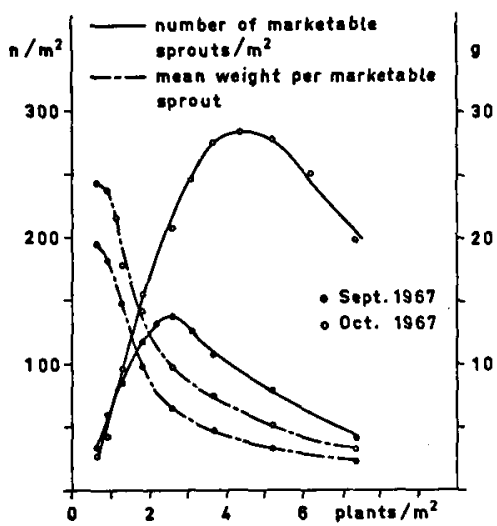

Fig. 11 The effects of crop duration on number and mean weight of marketable sprouts at varying density. 
With increasing crop duration the optimum yield is attained at higher density and as shown in Fig. 10 and 11 - yield levels at these higher densities increase tremendously from late September to late October. The optimum density for sprout number per $\mathrm{m}^{2}$ is higher than that for sprout weight per $\mathrm{m}^{2}$. This suggests that still higher yields might have been obtained on a later date, provided that sprouts had continued to grow. Sandwell (1969), working also with 'Thor' in 1965, 1966 and 1967, obtained the highest yields for stopped and unstopped plants in November; the density was almost 4 plants per $\mathrm{m}^{2}$.

\section{Effects of planting pattern and row orientation}

The effects of planting pattern and row orientation were small, if not negligible, in comparison with the density effects. The only influence of planting pattern which

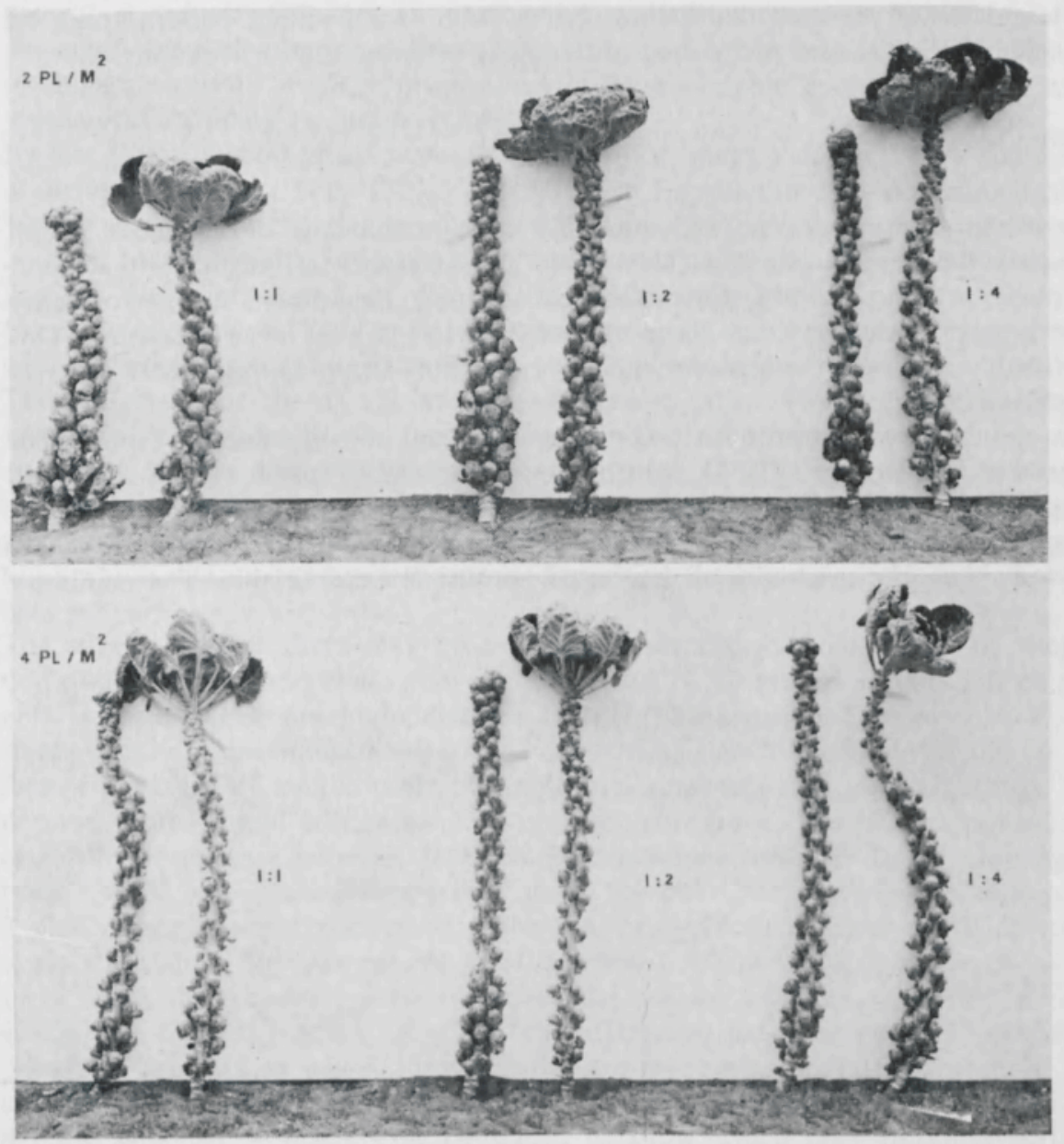

Fig. 12 The influence of the planting pattern - indicated by the inter:intra-row spacing ratio on plant habit and sprout production, at densities of 2 plants per $m^{2}$ (upper series) and 4 plants per $m^{2}$ (lower series), for stopped and unstopped plants at harvest, 24 October 1967. 
could be traced was an increase of plant height with increasing rectangularity of the planting pattern, at low density. This effect was found in both years and was most convincingly shown by the results of the randomized block trial. Fig. 12 shows the increased.height growth at prominent rectangularities; the picture suggests that at 4 plants per $\mathrm{m}^{2}$ also, plants were somewhat higher with increasing rectangularity, but this is not confirmed by the overall data.

There was a hardly perceptible tendency to higher plant weight in rows running eastwest. However in most fields the differences between row orientations were inconsistent, so the evidence is inconclusive. There is no evidence at all that plant habit and sprout production were affected by row orientation.

The absence of more prominent effects of the planting pattern is surprising, because the light measurements revealed substantial reductions of light interception for $2-3$ months from planting at extreme rectangularity, especially at low density. Differences in light interception between the two row orientations, on the other hand, were rather small. Haigh (1964) reported conflicting results from two planting pattern trials on sprout yield; both trials failed to show differences between row orientations.

\section{Discussion}

Feasibility of a single-pick harvest

To obtain high yields with a single-pick harvest simultaneous development of all sprouts along the stem is essential. This is the case if plants are sufficiently slender. Slender plants are also desirable for mechanical stripping. The design and performance of the stripping mechanisms can be perfected if stems are of even thickness. This would probably eliminate the loss of yield due to machine stripping, reported by Davies and Wheeler (1968).

Just how slender should plants be to produce well and to strip easily? Some clues for an answer are given in Fig. 13, which shows marketable sprout weight as a percentage of total sprout weight against slenderness, for three harvest dates. The weight percentage of marketable sprouts increases rapidly up to slenderness values of $8-10$ $\mathrm{cm}$ per $\mathrm{cm}^{2}$; thereafter virtually all harvested sprouts are marketable. The similarity

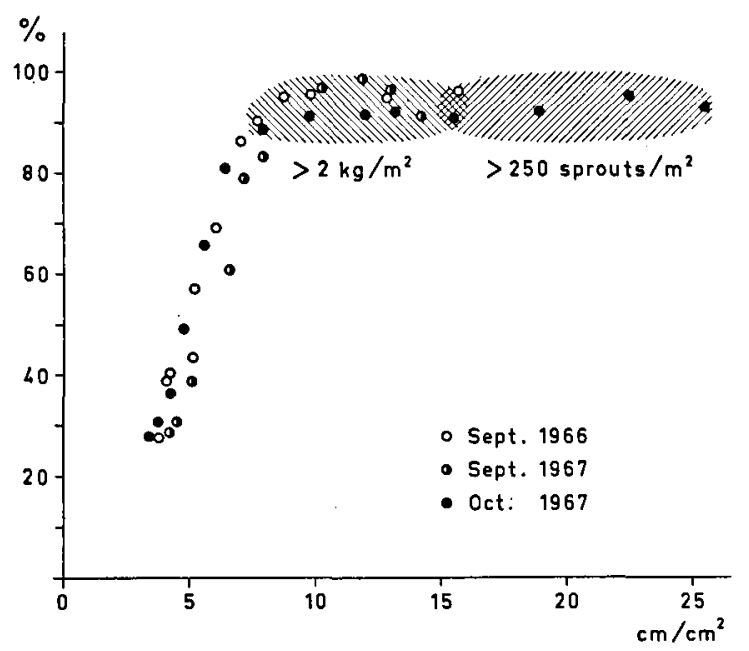

Fig. 13 Weight of marketable sprouts as percentage of total sprout weight in relation to slenderness, for three harvest dates. Shading marks trajectories of highest yield of marketable sprouts for the October 1967 harvest. 
of the relationship for all three harvests is striking. This suggests that 'Thor' plants with slenderness values of 10 and more yield little or no unmarketable sprouts, irrespective of crop duration or yield level. Moreover such plants are well suited to mechanical stripping. These two points are illustrated by the upper series of plants in Fig. 12, with slenderness values ranging from 7-10.

It is further indicated in Fig. 13 that for plants harvested in October 1967 the highest yields of marketable sprouts, both in weight and in numbers per $\mathrm{m}^{2}$, were obtained above this 'threshold slenderness' of $8-10 \mathrm{~cm}$ per $\mathrm{cm}^{2}$. This is not surprising, because at lower slenderness values market yield per $\mathrm{m}^{2}$ is reduced by an increasing percentage of unmarketable sprouts and by the low plant numbers per $\mathrm{m}^{2}$.

However sprout development in slender plants is retarded, so the potential yield of these plants can only be realized if crop duration is sufficiently long. Accordingly, for the September harvests in both 1966 and 1967, the highest weights of marketable sprouts per $\mathrm{m}^{2}$ were obtained at slenderness values of $6-10$, the highest numbers per $\mathrm{m}^{2}$ at values of $8-16 \mathrm{~cm}$ per $\mathrm{cm}^{2}$. For these 'premature' harvests, even small deviations from slenderness values of 8-10 caused either substantial yield depressions (at higher values), or large proportions of unmarketable sprouts and difficulties in mechanical stripping (at lower values).

By late October good yields were obtained over a much wider and very suitable range of slenderness values (Fig. 13). It appears from Fig. 12 that sprout quality in October 1967 was good for the slender plants. Moreover, the sprouts of these plants were so uniform that the yield could not have been much higher in case of multiple-pick harvesting. Yields of over $2 \mathrm{~kg}$ per $\mathrm{m}^{2}$ are indeed quite good by any standards. Thus Fig. 13 shows convincingly that high yields of good quality sprouts can be obtained with a single-pick harvest, from plants suited to mechanical stripping.

The uniformity of sprout size at high slenderness ratios makes it feasible to produce sprouts of a specific grade, for instance for the deep-freeze industry, by a proper choice of density and crop duration. Because of this uniformity mean weight per marketable sprout is a useful characteristic of sprout grade at higher density. Thus, given the relation between mean weight and grade, Fig. 11 shows for two crop durations which density produces the desired grade and the corresponding yields in numbers per $\mathrm{m}^{2}$.

The suggestion that there may be a threshold slenderness, unaffected by crop duration and growing conditions, above which virtually all picked sprouts are of marketable size and yields are high, deserves further consideration. Supposing that a fairly stable threshold does indeed exist, practical spacing recommendations could be derived from comparatively simple trials. A single trial comprising an adequate range of slenderness values would suffice to determine the threshold. The next step would be to establish the relation between density and slenderness under different growing conditions. Fig. 5, for instance, shows that under the poor 1966 growing conditions almost 3 plants per $\mathrm{m}^{2}$ were required to reach the threshold slenderness of $10 \mathrm{~cm}$ per $\mathrm{cm}^{2}$, against less than 2 plants per $\mathrm{m}^{2}$ for the heavy 1967 crop.

In this way the threshold slenderness and the spacing required to realize it, could be established for any variety. Apart from differences between varieties, the threshold obviously depends on which sprout grades are to be marketed; the threshold will for instance be higher for deep-freeze sprouts than for fresh market sprouts. With a view to crop planning it would also be useful to know which crop duration suffices for sprouts at the threshold slenderness to reach marketable size and to what extent this period can be shortened by stopping. 


\section{Spacing and mechanization}

As discussed before, the main link between spacing and mechanization lies in the slenderness of the plants, which largely determines the performance of mechanical strippers. The improving uniformity of the sprouts with increasing slenderness and the absence of big unmarketable sprouts above the threshold slenderness also simplify the grading operation.

The increase in crop height at close spacing requires more clearance for tractors and machines to be used in the standing crop. Access to the crop seems very desirable, be it for top dressing with fertilizers, for pest control, or perhaps for chemical stopping of the plants (Thomas and Comber, 1967). Row cropping would improve the accessibility of the crop; the results indicate that if planting on the square is replaced by rectangular planting patterns plants grow more slender, especially at low density. The weight of vegetable matter transported to the shed for stripping amounted to 5 and $12 \mathrm{~kg}$ per $\mathrm{m}^{2}$ in 1966 and 1967 , respectively. This corresponds to $50-120$ tons per ha and explains the interest in tools or chemicals which can be used to defoliate the crop prior to harvest. Experiments of Garthwaite (1968) show large reductions in yield if leaves are removed two weeks or even one week before harvest. Defoliation therefore should be postponed as long as possible. The 'picking mobile' (Moltzer, 1968), with a series of strippers mounted on a carrier, provides a further possibility for restricting transport.

\section{Acknowledgment}

The author expresses his appreciation for the competent assistance of Mr F. L. J. A. $\mathrm{W}$. Verwer, horticulturist at the institute and $\mathrm{Mr} \mathrm{H}$. Storm, student at the Agricultural University, Wageningen. The co-operation of Dr M. A. J. van Montfort and Mr T. A. Reesinck, statisticians of the Dept of Mathematics, Agricultural University, Wageningen, who computed the data of the systematic spacing experiments, is also gratefully acknowledged.

\section{References}

Bleasdale, J. K. A., 1967. The relationship between the weight of a plant part and total weight as affected by plant density. J. hort. Sci. 42: 51-58.

Bleasdale, J. K. A., 1966. Plant growth and crop yield. Ann. appl. Biol. 57: 173-182.

Carter, A. R., 1962. The stopping of Brussels sprout plants. Expl. Hort. 7: 7-15.

Davies, A. C. W. \& J. A. Wheeler, 1968. Effect of machine stripping on the yield and grade of Brussels sprouts. J. agric. Engng Res. 13 (3) : 241-244.

Donald, C. H., 1963. Competition among crop and pasture plants. Adv, Agron. 15: 1-118.

Garthwaite, J. M., 1968. Brussels sprouts : production of early crops. Expl. Hort. 18: 60-68.

Haigh, J. C., 1964. Spacing trials with quick-freeze Brussels sprouts. Expl. Hort. 10: 80-89.

Moltzer, F., 1968, Plukmachines voor énmalige spruitenoogst. Publ. Inst. Tuinb.Tech. 35 (Part 1); $2-6$.

Nelder, J. A., 1962. New kinds of systematic designs for spacing experiments. Biometrics 18: 283-307.

Nieuwhof, M., 1962. Het verband tussen de rassenkeuze bij spruitkool en de wijze van oogsten. Meded. Dir. Tuinb. 25 : 418-423.

Sandwell, I., 1969. Factors affecting the maturity date of Brussels sprouts grown for single pick harvests. Acta hort. (in press).

Thomas, T. H. \& M. Comber, 1967. Plant hormones: chemical stopping of Brussels sprouts. Rep. natn. Veg. Res. Stn $18: 45$.

Wit, C. T. de, 1960. On competition. Versl. Landbouwk. Onderz. 66.8, pp. 82. 